\title{
Exploration of Route to Establish the Office Administrative Management Matching the Key Colleges
}

\author{
Lili Xu \\ Chengdu Polytechnic, 610041 Chengdu Sichuan, China
}

\begin{abstract}
Based on the analysis on the main problems in office administrative work in the modern higher vocational colleges, I put forward some suggestions on improving the office management by changing administrative management idea, strengthening the service consciousness and professional skills, perfecting the rules and regulations, enhancing staff training and so on.
\end{abstract}

Keywords. higher vocational college; office; administrative management level

\begin{abstract}
Higher vocational college office is a comprehensive service department directly led by the college and the pivot of normal operation of management work for the whole college. It plays a transitive, coordinative, all-round connective, contacting and binding role; It also plays a role in the information passage, policy research, helping leaders on decision and assistance. Currently with the increasingly deepening of teaching reform for national key higher vocational colleges and the increasing number of teachers and students, the management work in the office becomes more arduous, and the content is also preciser. How to improve the management and service level for higher vocational college office is the key problem for "key construction". To accept the pressure and challenge from the construction of key higher vocational colleges, the office shall positively improve its own level of management and service work and promote the management level of higher vocational college to a higher notch.
\end{abstract}

\section{Current situation of administrative ma- nagement for higher vocational college office}

\subsection{Out-of-date management and lack of human- ization in the system}

In view of the current situation, the daily operation of administrative management for higher vocational college mainly depends on the leaders that command or formulate each regulation to limit the behaviors of each functional department by their own administrative rights. To a certain extent, this method is reasonable to regulate the management order and ensure the smoothness of government decree. While it will also lead to the sole compliance of functional departments with the arrangement of leaders and passively perform the work without any remaining effort on the innovation and research on the modern administrative management system for the construction of key colleges, which prevent the exertion of creativity. Currently, many higher vocational colleges use this kind of management method. The operators put more thought on the satisfaction of leaders and the recognition therefrom, while putting less or no thought on the opinions of numerous teachers when making decision. The transparency and communication degree of administrative management is not enough, and the purpose of mass line education practice activity is not implemented either. They simply see the teachers and students, the main body of college, as the objective of management but not the service, and the management system lacks the sufficient humanization.

\subsection{Insufficient importance on the administrative management specialization}

The administrative management of higher vocational college has technical, scientific, specialized and academic features. The level of administrative management team in higher vocational college determines the scientificity and advancement of college management, and also plays a key role for the rapid development of colleges. While many higher vocational colleges just simply focus on the "key" construction. They do not realize that the administrative management is a managing activity with extremely strong operability or focus on the innovation of administrative management mechanism. The administrative management staff in higher vocational college has a complex work. They are busy dealing with various document requirements and daily business from superior every day, and what they have done often will fail to be 
recognized by the front-line staff of scientific teaching research. In case they made mistakes in the work, they would be scolded, and we may feel that they are just kept constantly on the run. Currently, the education and training opportunities for administrative management team in higher vocational college are few, and it's hard for them to go out to study and communicate with others. Furthermore, they receive insufficient systematic training, have difficulty in conferring of academic titles and less opportunity for further education, which directly affect the activity, positiveness and creativity of administrative management staff in their work, and limit the improvement and development of professional quality of the team, as well as the construction of key colleges.

\subsection{Poor awareness of "key construction" in the administrative management team}

The administrative management staffs are the executor of the policy, the completer of the core tasks in the college, the establisher of scientific research plan in the higher vocational college and the implementer and coordinator of various activities. So they shall be familiar with each administrative management systems and master the basic procedure and methods for each management activities. While currently, there's a huge gap between the capacity of the administrators in the higher vocational college and those requirements, and the working level stays simply in the understanding of the previous experience. They do not make extensions and are hard to achieve innovation. They fail to actively adapt to the construction of key colleges. There are no scientific and reasonable human resources to optimize the administrative management, efficient standard of qualification for the administrative management staff or the focus on the construction of administrative management team. The higher vocational college shall be subject to sustained development, improve the professional competence of administrative management staff, change their working methods, creatively exercise the subjective initiative, establish the teamwork spirit and the awareness of positive implementation of various works based on joint construction of "key college".

\subsection{Imperfect salary management system}

It is reported that currently, the management system of salary in higher vocational college is not flexible due to the lack of "varied systems for different colleges". Some colleges do not formulate a salary standard for administrative management staff according to the economic level of the corresponding regions. They almost use the "same" method to distribute the salary without establishing the salary management system suitable for their own features according to the development strategy and economic conditions of their own. As in the annual evaluation process in a technician college, they are not evaluated according to their performance or confirmed standard but the relation, human relationship, reputation, etc.. They even implement the methods of being "advanced staff" "in turn", which make the "real advanced staff" lose the confidence and the "fake advanced staff" never march forward. Furthermore, in the higher vocational college, the salary level for administrative management staff is lower than that for scientific teaching research staff, and the part-time teachers even have discounted salary, which deprive them of enthusiasm, activity and initiative in the working. In fact, the administrators in the higher vocational college are often the ones with comprehensive qualities of educational teaching and working capacity "at the same time". But the salary allocation are extremely varied for them.

\section{Main factors that affect the manage- ment working level of higher vocational college office}

\subsection{The reasonable software and hardware is the premise to improve the management level}

The development of information technology rapidly makes the paperless working common, and the administrative management field in the key higher vocational colleges shall make use of this function. The scientific and reasonable hardware equipment is the security of normal operation of management service provided by higher vocational college office. These hardware equipment includes high-performance computer, network device, printer, photocopier, fax and various stationery and paper.

The relevant working procedures of higher vocational college office include the document circulation procedure, working procedure for meeting, working procedure for receipt, working procedure for notice, scientific dispatch of vehicles, etc.. In the daily working of higher vocational college office, the interception of working functions, evasion of responsibilities, the fear of undertaking the responsibilities and other situations for the clerks may induce the low administrative efficiency in the office. Apart from the necessary hardware facility, we shall also constantly formulate and perfect the relevant working systems, clarify the post duties, prevent the "fault" or "vacancy" in the management work and realize the comprehensive and refined operation of management and specification.

\subsection{Improving the staff quality in multiple as- pects is the key to improve the management work}

As known to everyone, as the main body of administrative work in the higher vocational college, the office administrative staff is the key for the management service of higher vocational college office. The quality of staff affects the operation of the whole college and the management work level in the office. To improve the administrative management working level of higher vocational college office, we shall strengthen the quality cultivation for the staff, comprehensively improve the quality and capacity of the staff and create a modern vocational teaching management team that is brave, capable, professional and matching the key colleges. 


\subsection{Scientific management is the powerful secu- rity for the improve of working level in the office}

Similar to the software and hardware facility and the quality of staff, the scientific management of daily work in the office is also the important security for the efficient operation of management service provided by higher vocational college office. If without the perfect system, it is inconceivable to well perform the office work. We shall focus on the systematic construction of the system to provide each aspect and link in the office work with systems to be based on and make the administrative management work in the height office adapt to the new development and requirement of colleges. Due to the heavy works and duties in the office work, each staff shall establish the awareness for the overall situation, understand and master the current or future development trend of the colleges and consider and position each office work according to the overall situation.

\section{Detailed measures to improve the ad- ministrative management working level of higher vocational college office}

\subsection{Actually change the administrative manage- ment concept and strengthen the service aware- ness and business level}

This is the first year for "comprehensive deepened reform". We shall make a complete reform firstly in the concept. As the prime ideology awareness of administrators, The service concept is significant for the efficient implementation of management service practice. Some administrative management staff in the higher vocational college office has an improper self-positioning and a poor awareness of service. This traditional administrative management concept has an adverse impact on the current administrative management system reform of higher vocational college. To improve the administrative management working level of higher vocational college office, we shall actually change the management concept, update the ideology and strengthen the service awareness of administrative management staff in the office. Providing the quality service for the numerous teachers and students based on their basic interests is the basis of sustained development for higher vocational college, and meanwhile the key to improve the competitiveness and extend the recruitment for the key higher vocational colleges. We shall establish and perfect the efficient management mechanism to keep the high enthusiasm in the work for the administrators in higher vocational colleges and ensure the realization of each educational purpose.

\subsection{Facilitate the improvement of administrative efficiency and focus on the system construction}

To improve the administrative efficiency of higher vocational college, we shall first pay attention to the system construction to form the staff and colleges treatment based on the system, to maximize the administrative management efficiency. The following aspects of system construction shall be focused on:

1) Complete the post allocation for all the staff and clarify the post duties. We shall confirm the fixed working duties in each post in the form of system to ensure that there's always an undertaker of a post duty. Perfect each appraisal and bonus mechanism and clarify the detailed procedures and requirements for title evaluation, attendance appraisal, bonus evaluation, etc., which may not only improve the efficiency, but also evade the disputes.

2) Form the survey system, strengthen the communication of management information and improve the timeliness of working. The higher vocational college shall positively extend the communication channel, widely receive the opinions from all the people in decisionmaking and fully communicate with the teachers and students. As the assistant of leaders, the office administrative management staff shall often go down to the grass-roots to know about the conditions and provide the detailed materials for leaders. Strengthen the communication and cooperation of each functional department, ensure the smooth circulation of information in the college and improve the working efficiency. Each work shall be provided with a detailed time limit and shall not be delayed or evaded, for the purpose of further improving the efficiency of administrative management.

3) Correct the service attitude and form a service type management system. We shall incorporate the index for key colleges, formulate the daily code of conduct for administrators, clarify the evaluation standard of service quality, clarify the working duties for each, intensify the working guidance in department and implement the management by objective.

\subsection{Constantly improve the staff quality through high-standard training}

The high-quality administrative management staff and high-level educational training are closely related, and the training shall be implemented according to the development orientation of the administrative management staff. By diploma education, post training or other methods, we may encourage the management staff to get the higher degree or participate in the high-level post training to accumulate the modern management knowledge and working experience, gradually improve their management level and reach the administrative management standard of key colleges.

\subsection{Formulate a perfect salary system}

Each staff cares for the salary standard, so the nonscientific allocation system will always be a "stumbling block" for the orderly development of working. The management staff in the higher vocational college shall be divided into different post levels, and different posts shall be provided with management staff with varied post levels. The management of employment, appraisal, training and other aspects for different posts, post levels and post grades shall be varied. To strengthen the activities of 
administrative management strengthen, the higher vocational college shall prepare a salary management system matching the administrative management post and reduce the income gap between the administrative management staff and scientific teaching research staff. The comprehensive improvement of salary for administrative management staff may induce larger attraction to the management post and retain the high-level management talents.

\section{Conclusion}

In summary, the administrative management work in the higher vocational college office is very complex, so the realization of refinement, standardization, institutionalization and specification is an important basis and condition for scientific management. With the rapid development of higher vocational education, the key higher vocational colleges shall be the pioneers to comprehensively deepen the reform, innovate the management capacity, accelerate the development of modern vocational education, innovate the vocational education mode to make the vocational education constantly produce the talents and dividend for our country and society.

\section{References}

1. Chen Hong, Lu Yan \& Chen Wei. Brief discussion of quality cultivation for administrators in higher vocational college office [J]. Medicinal Management Magazine, 2010, (7).

2. Lu Qing \& Yang Shiping. Centering and coordinating to improve the service level of office [J]. Office Business, 2006, (1).

3. Wang Qiang. Discussion on the professional construction problem of administrative management team in higher vocational college [J]. Vocational Technical Education, 2012, 11. 